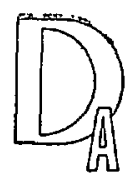

HOCUNENTA CHON

\title{
CRONICA S \\ EL INVENTARIO GENERAL DE BIENES \\ Y DERECHOS DEL ESTADO
}

$657.371: 336.1(46)$

\section{Ambito del inventario general}

El inventario se concibe-dice la exposición de motivos de la Ley de Bases del Patrimonio del Estadocomo un instrumento administrativo con trascendencia superior a la del mismo Patrimonio. Así lo aconseja -sigue el preámbulo- la necesidad de un conocimiento total de los bienes del Estado y la posibilidad, siempre presente, de la incorporación al Patrimonio de los bienes demaniales.

El Inventario, según la base XXIII de la propla Ley, comprende todos los bienes y derechos del Estado, cualquiera que sea su naturaléza, la forma de adquisición y el Departamento y Organismo que la haya realizado.

A pesar de su nombre, el inventario que contempla la base XXIII no es, en realidad, general, sino más bien parcial, pues constituye la fracción que, dentro del Ministerio de Hacienda, corresponde realizar a la Dirección General del Patrimonio del Estado en un inventario que, por contraposición, debería denominarse «total». Este inventario total es aquel 
que puede conducir a un balance general de la Hacienda pública, correspondiendo realizar a otros centros del Ministerio (Tesoro, principalmente) las partes restantes del mismo.

El inventario de bienes y derechos se integra totalmente en el activo; en cambio, otras partes de inventario total pueden integrarse en el activo (inversiones, créditos, etc.) o en el pasivo (Deuda, etc.).

Para una mayor precisión del ámbito del inventario podríamos decir que el "general» comprende los bienes y derechos cuya administración se rige por normas de carácter privado, $y$ que indistintamente se aplican a tres grupos de bienes, todos ellos estatales, pero de distinta significación: 1, los patrimoniales enajenables; 2 , los patrimoniales integrados en el sector comercial e industrial al que directamente se halla a cargo de la Administración, y 3 , los servicios públicos que integran el "establecimiento» del Estado. Deliberadamente hemos separado un cuarto grupo, al cual, sin duda, también afecta el inventario general, pero a cuyos bienes creemos conviene más el nombre de «nacionales». Son los de la Renfe, los de la Banca oficial, los del Instituto Nacional de Previsión y quizá también, por la especial misión que cumplen, los del Patrimonio Forestal.

Los grupos de bienes denominados patrimoniales, del "establecimiento» del Estado, y de dominio y uso público constituyen tres vasos en continua comunicación, por la susceptibilidad que tienen los de una naturaleza en adquirir cualesquiera de las otras, por lo que es aconsejable conocer al menos las características físicas de los de uso público; por tanto, se siente la necesidad de que órganos especializados, más o menos esquemáticamente, formen un catálogo general de estos últimos, el cual podría dividirse asi: a) Vias públicas (carreteras, ferrocarriles y vías pecuarias) ; b) Zona maritimo-terrestre, y c) Cauces fluviales interiores.

\section{II. ¿Qué es el inventario?}

Anticipemos que el inventario no es un fin, sino el medio de que la Administración se vale para la consecución de determinadas finalidades, y que, como todo lo que con la contabilidad y la estadística se relaciona, el inventario es un servicio de carácter informativo.

Uno de sus objetos es formular cifras-índice cuyo conocimiento haga posible la adopción de acertadas normas de administración y contabilidad patrimonial, y otro no menos importante, el poner de manifiesto el potencial económico del Estado.

Cumple por tanto el inventario la misión de ponernos de manifiesto claramente la calidad y cantidad, el conjunto y el detalle, de cuanto poseemos y cómo lo tenemos distribuído para, en su vista, deducir si es suficiente y adecuado y.si, para el debido equilibrio de los servicios oficiales, se halla bien o mal distribuído.

Sin duda con propósito de organizar diversos ficheros ha exigido la Dirección General del Patrimonio del Estado varios ejemplares de fichas de características. Aun cuando estamos ante una cuestión opinable, existen razones para pensar en la conveniencia de que se establezca un fichero general en la Dirección General del Patrimonio del Estado, otro central en cada Ministerio $y$ uno provincial en cada Delegación de Ha- 
cienda; pero ésta es una cuestión que no puede decidirse en tanto no se resuelva la forma en que se ha de implantar la contabilidad patrimonial.

En teoría, el inventario debe depender de un archivo patrimonial, pero la ordenada formación del mismo, sobre todo en lo que se relaciona con bienes y derechos ya poseidos, puede exigir tanta paciencia y esfuerzo como la conclusión del inventario; por ello se dibuja, más que como tarea anticipada, como misión simultánea a la de inventario. Los posibles fallos de este archivo, o la formulación anticipada del inventario, exige la colaboración de los funcionarios responsables de la custodia, conservación y aplicación de los bienes y derechos, así como la de expertos en apeo y valoración de bienes.

La Real Academia define el inventario diciendo que es el asiento de los bienes y demás cosas pertenecientes a una persona o comunidad hecho con orden y distinción.

Por otra parte, se ha venido considerando al inventario como un registro capaz de dar fe por si mismo de las pertenencias del Estado, siendo esta idea, a nuestro juicio, equivocada, al menos en cuanto a los bienes patrimoniales, pues no constituye en estè aspecto más que un instrumento de régimen interior de la Administración, y que, por tanto, tiene muy relativa significación frente a personas ajenas a la misma. Una cosa es que el inventario deba conducir a la regularización de la situación jurídica y administrativa de los bienes del Estado, en cuanto que es un mecanismo que pone al descubierto sus caracteristicas administrativas, físicas, jurídicas y económicas, y otra muy diferente que supla a los títulos de dominio y sustituya la función atribuída al Registro de la Propiedad.

El artículo 5. del Reglamento Hipotecario (Decreto de 17 de marzo de 1959) indica que quedan exceptuados de inscripción los bienes de dominio público a que se refiere el artículo 339 del Código Civil, «ya sean de uso general, ya pertenezcan privativamente al Estado, mientras estén destinados a algún servicio público». El articulo $6 .^{\circ}$ puntualiza que si alguno de estos bienes cambiare de destino y adquiriere el carácter de inscribible, se llevará a efecto su inscripción. Contrariamente, si un inmueble de propiedad privada adquiriere la naturaleza de los enumerados en el artículo 5. , "se hará constar esta circunstancia por nota marginal».

Hasta aqui todo es correcto, pero el último párrafo del artículo 18 dice que "los cambios de adscripción de los bienes del Estado... podrán inscribirse mediante el traslado de la disposición administrativa correspondientes.

La contradicción que observamos entre los preceptos anotados es la siguiente: Si se hallan exceptuados de inscripción los bienes del Estado mientras están destinados al servicio público, ¿por qué razón nos instruye el Reglamento Hipotecario sobre la forma en que se "pueden» inscribir los cambios de afectación? Otra pregunta nos queda por hacer: ¿Exige el Reglamento Hipotecario a los propietarios privados que den cuenta al Registro de los cambios de aplicación de sus bienes?... Si no tiene tal exigencia en caso de bienes patrimoniales y propietario privado, ¿por qué la tiene cuando el propietario es el Estado y los bienes son de servicio 
público?... Sinceramente creiamos que la institución llamada por naturaleza a dar testimonio de los cambios de afectación de los bienes de servicio público era el inventario $\mathrm{y}$ no el Registro de la Propiedad.

Volviendo a nuestra idea anterior diremos que lo que siempre será actual es aquello de "hecho con orden y distinción», porque $\sin$ distinción ni orden no hay inventario posible. Las distinciones empiezan en el momento mismo en que se procede a inventariar, pues hay que distinguir unos bienes o derechos de otros, por su naturaleza, por su condición jurídica, por su afectación, por su procedencia, etc. El orden en inventario debe ser riguroso y afectar tanto a lo particular como a lo general, al fondo como a la forma, pues es la esencia misma del inventario, en tal manera que el orden de éste debe proceder del reinante en el archivo patrimonial $y$ trascender del inventario, que es el' vehículo del orden patrimonial, a la administración, a la contabilidad, a la estadística y a todos los demás aspectos que el $\mathrm{Pa}$ trimonio implica.

Para mantener el orden en inventario tan complejo como el del Estado se debe exigir que, del principio al fin, los caminos que hayan de recorrer bienes y derechos se tracen lo más rectamente posible, y las formalidades a que aquéllos se hayan de someter se establezcan con entera claridad.

Sin inventario no puede haber arreglo en la conducta patrimonial; no puede haber ni siquiera conducta, pues se está en la posición del que ignora su ser y poseer.

La programación de nuevas adquisiciones, la conservación de cuanto se posee y la enajenación, a su debi- do tiempo, de lo innecesario o inútil no es posible llevarla a cabo racionalmente sin la información del inventario general. Las adquisiciones - enajenaciones realizadas por los organismos, como si fueran compartimientos estancos, tienen el peligro de que se adquiera lo que a otros organismos sobra, o que se enajene lo que otros organismos necesitan, y hasta de que el Estado adquiera del mismo Estado (ventas de unos organismos oficiales a otros).

\section{Planificación y entidad de los trabajos de inventario}

Aun cuando sea arriesgado trabajar en una actividad parcial sin tener planificada la materia general, debe admitirse que en inventario pueden iniciarse algunos trabajos siempre que se desenvuelvan dentro de determinadas áreas; pero, con todo y con eso, parece que sería conveniente determinar anticipadamente: 1) qué bienes, por su importancia económica o de otro orden, deben inventariarse individualmente (inventario analítico o de primer grado); 2) qué otros, por su gran profusión y poco valor relativo, unidos a otras singularidades, se deben inventariar colectivamente (inventario sintético o de segundo grado); 3) en qué especies o bienes, por su poco valor efectivo, por permanecer escaso tiempo en manos de la Administración, etc., en lugar de inventario permanente debe hacerse tan sólo «relación de existencias en fin de ejercicion, y 4) finalmente, qué especies, de bienes o derechos, se deben clasificar como "exceptuados de inventario». El control de los bienes exceptuados de inventario parece que debe quedar a 
cargo exclusivo de la unidad orgánica a que estuviesen adscritos, y posiblemente deba ocurrir lo propio con los sometidos a relación de existencias en fin de ejercicio.

La señalización es otro de los muchos problemas anejos al inventario, y debe tener por base normas comunes para toda la Administración. Sirve principalmente al inventario, y por tanto las normas deben impartirse desde el Ministerio de Hacienda y afectarán a todos los demás Departamentos; pero no por ello debe despreciarse la utilidad que la señalización de plantas y locales representa en cuanto a circulación del público y localización de servicios en los centros oficiales. Los distintivos de la señalización y los destinados a marcar los bienes muebles deben ser uniformes para toda la Administración, y haría bien el Ministerio de Hacienda en facilitarlos a todos los servicios oficiales.

Como carecemos de una base formal para estimar lo que puede representar el inventario en cantidad y calidad de trabajo no nos queda más remedio que suponerlo:

Carpetas de archivo con antecedentes patrimoniales, 250.000 .

Fichas de caracteristicas (originales), 250.000 .

Copias para los diferentes servicios, 750.000 .

Fichas perforadas para contabilidad y estadística, 250.000 .

Cuentas a manejar, 1.000 .

Además del trabajo que representa la ejecución del supuesto anterior hay que contar con la formulación de un diccionario que comprenda todas las voces que puedan referise a bienes y derechos del Estado, indicando en cada una de ellas la cuenta que debe recoger sus valores representativos. Este diccionario debe llevar como apéndice el clasificador de cuentas, determinando expresamente en cada una de ellas su contenido.

El inventario, con su antecedente inmediato, el archivo patrimonial, y sus inmediatas consecuencias, la contabilidad y estadística, se sitúa como un núcleo central alrededor del cual giran diversos servicios concomitantes $\mathrm{y}$ que por sus mutuas influencias exigen planeamiento y resolución concorde y simultáneas. Tales son los siguientes: 1 , administración de bienes y derechos, lo que comprende la adquisición, construcción, fabricación, conservación, afectación y enajenación; 2, clasificación de bienes y derechos; 3 , tipificación convencional y efectiva; 4, estimación o corrección de valores en venta $y$ renta $y$ determinación de los ciclos de su vigencia, según naturaleza, afectación y radicación de los bienes; 5 , concordancia de inventario y registros públicos; 6 , señalización de plantas y locales en que se hallen instalados los servicios del Estado, sean o no propiedad del mismo; 7, marcaje de todos y cada uno de los bienes de carácter mueble, anotando serie, tipo, cuenta y número de inventario, y 8 , diccionario de voces y clasificador de cuentas. Todos estos servicios son como miembros de un mismo cuerpo, del que forma cabeza el inventario.

\section{Clasificación de bienes y datos mínimos exigibles en contabilidad y estadística}

La clasificación de bienes y derechos, a efectos de inventario, contabilidad y estadística, ciertamente es una materia convencional, pero no 
se pueden sentar criterios sobre la misma sin tener presentes el ámbito y los propósitos finales de tales instituciones. De cualquier forma, esos criterios deben establecerse de antemano en cada fracción patrimonial. Es aconscjable una posición intermedia, situada entre lo exhaustivo y lo extremadamente simple, pues lo primero puede resultar demasiado laborioso y confuso, y lo segundo, por carecer de significación, con falta de los adecuados matices.

Las últimas ramificaciones de la clasificación de bienes y derechos pueden presentar problemas, sobre todo cuando se trate de bienes creados por el hombre, lo que puede exigir la presencia de expertos para establecerla, como puede acontecer con maquinaria, vehiculos, etc.

Con estas reservas intentemos hacer un esquema de clasificación: los bienes pueden ser inmuebles o de carácter mueble. Los primeros se ramifican en patrimoniales o de servicio público, y los segundos, en reales, de arrendamiento o incorporales. Los patrimoniales, sean bienes o derechos, muebles o inmuebles, pueden ser con destino (Torrevieja, Almadén) o vacantes (fincas adjudicadas por débitos). Los que tienen destino pueden ser de explotación directa (Almadén) o indirecta (Torrevieja). Los bienes sin destino deben clasificarse por procedencia (adjudicadas, desafectados, segregados del uso general, mostrencos, etc.).

Atendida su adscripción, los servicios públicos, bienes $y$ derechos, muebles e inmuebles, pueden separarse por affectaciones (clasificación orgánica). Dentro de cada Departamento, según se hallen adscritos a servicios centralizados o descentralizados. Cuando un servicio acuse, por cantidad o calidad de bienes, personalidad suficiente, será preciso ramificarlo a su vez, tal y como puede suceder con Enseñanza (primaria, secundaria, universitaria).

Partiendo del sistema decimal y teniendo en cuenta la naturaleza de los bienes, parece forzoso ramificar el tronco en diez especies, para obtener sucesivamente (de diez en diez) clasificaciones secundarias, terclarias, etc. Los diez primeros grupos, aun cuando esta materia, como otras tantas de inventario, es opinable, pueden ser quizá los siguientes: 1. Inmuebles. 2. Vehículos y material de transporte. 3. Mobiliario, objetos de adorno, iluminación, calefacción y útiles varios. 4. Bibliotecas, Museos y otras colecciones (artisticas, científicas, etc.). 5. Generadores de energia, máquinas $y$ herramientas. 6. Armas. 7. Valores mobiliarios. 8. Semovientes. 9. Fungibles y de uso precario (si no se exceptuan de inventario). 10. Derechos.

A la clasificación jurídica puede aplicarse la orgánica; a la orgánica, la basada en la naturaleza de los bienes, y a las tres otra más, por áreas geográficas (región, provincia, municipio). De cualquier forma, la clasificación definitiva debe establecerse en función de las exigencias de la contabilidad y de la estadística.

Si para una división secundaria tomamos a los inmuebles, éstos pueden dividirse en fincas rústicas, edificios y solares y obras e instalaciones. Las fincas rústicas pueden dividirse así: montes y parques, fincas agrícolas, granjas y campos de experimentación, fincas de carácter extractivo (minas, salinas y cante- 
ras) y manantiales, cursos de agua, lagos y lagunas.

En edificios y solares, la clasificación puede ser la siguiente: solares, con - o sin destino, y edificios con destino a los siguientes servicios: gubernativos, de carácter comercial, a servicios castrenses, a fines turísticos y deportivos, a viviendas.

En obras e instalaciones, la clasificación terciaria puede ser: captación, embalse, almacenaje, conducción y distribución de líquidos y gases, comunicaciones $y$ transporte de energía, zonas de servicio (puertos, aeropuertos, etc.), complejos industriales, señalizaciones, ferrocarriles, depósitos independientes (para áridos, liquidos y gases), diques, muelles, murallas y obras de defensa (no castrenses).

El grupo de vehiculos exige una clasificación secundaria según su naturaleza, separando, en efecto, los que circulan por tierra, mar y aire; una terciaria, según los diferentes sistemas o clases de tracción, y una última por prototipos.

Las clasificaciones finales que sea conveniente establecer, tanto por naturaleza, por afectación o por radica.ción, deben determinar las cuentas individuales de que ha de constar la contabilidad patrimonial.

Las fichas puestas en circulación para inmuebles del patrimonio inmovilizado, por la Dirección General del Patrimonio del Estado, tanto por su estudiada estructura, cuanto por su minucioso detalle en lo relativo a características sirven, más que para inventario, para la administración de los bienes. La contabilidad y la estadística, por ser más sintéticas, deben apoyarse en fichas perforadas, las cuales, aparte los datcs conducentes a las diferentes cla- sificaciones que deban hacerse en bienes $\mathrm{y}$ derechos, básicamente deberán expresar lo siguiente: cantidad, superficie, medida, peso, potencia o capacidad, coste, valor calculado y producto y gasto anual, real y calculado. A este esquema pueden añadirse cualesquiera otros datos, a condición de que en las respectivas especies o tipos de bienes aparezcan en forma constante y se puedan expresar numéricamente.

\section{Tipificación de bienes}

La tipificación es uno de tantos problemas consustanciales con el inventario. No puede haber inventario, al menos por lo que se refiere a bienes de carácter mueble, sin previa tipificación.

No es un invento moderno este de la tipificación de bienes, pues desde antiguo algunas ramas de la Administración, por fuerza de las circunstancias en que se desenvuelven, han tenido que aceptar la tipificación. Es la tipificación exigencia inexcusable en algunas esferas de la Administración en cuanto manejan masas, de personas o de cosas (funcionarios, estudiantes, soldados, enfermos, etc.), sometidas a un exponente común. La tipificación es condición previa necesaria para que sin esfuerzo la mente humana comprenda esa cosa cuantiosa y compleja que es la Hacienda que en bienes y derechos posee el Estado.

Desde el punto de vista de inventario, la tipificación entraña dos conceptos diferentes: el de la tipificación convencional y el de la tipificación efectiva. Esta última se refiere al futuro y es una exigencia in- 
aplazable, tanto para el buen rendimiento de los servicios cuanto para la buena administración patrimonial. La tipificación convencional es la que se debe implantar, con referencia a los bienes ya existentes, para facilitar las labores de inventario, pues no se debe pretender que, en mobiliario, por ejemplo, se registren uno por uno los infinitos tipos de mesas, sillas y armarios que efectivamente existen, ya que entonces la labor sería prácticamente irrealizable. Nos hallamos, pues, obligados a realizar una tipificación convencional para que el inventario pueda ser una realidad, para reducir el infinito número de tipos reales a cantidades convencionales, pero contable $\mathrm{y}$ estadísticamente manejables. Para que ciertos bienes deban ser incluídos dentro de determinado tipo, se requiere la coincidencia de ciertas analogías, como la de adscripción, materiales que los integren, capacidad, peso, valor, etc.; todo ello dentro de unos cuadros de tolerancia previamente establecidos.

La tipificación real, además de las ventajas de orden administrativo atribuídas a la convencional, permitirá una programación de adquisiciones, e incluso de enajenaciones, con márgenes económicos enormes, derivados de la masificación de estas operaciones. Permitirá igualmente el intercambio de bienes entre distintos Organismos, y convertirá en aprovechable todo el equipo adscrito a Organismos que se refunden, desdoblan o suprimen, en el continuo tejer y destejer de la reforma orgánica, derivada a su vez del permanente estado de metamorfosis en que se halla la Administración pública.

\section{Valoración y amortización de bienes del Estado}

Anticipemos que en el Estado los criterios deben basarse en razones técnicas, y no en sofismas dirigidos a. falsear el potencial económico.

Aun suponiendo que el Estado pueda o deba desentenderse al menos de parte de estas cuestiones, por tratarse de un negocio sui generis, le quedan por resolver los $\mathrm{mu}$ chos problemas que crean la cuantía y variedad de su acervo patrimonial, asi como las diferentes situaciones en que puedan hallarse los bienes.

La fórmula usual de valoración $\mathrm{y}$ amortización anual, salvo en algún sector comercial, es, desde luego, materialmente impracticable para el Estado; por ello viene obligado a buscar otras que le permitan realizar valoraciones masivas y por ciclos. A nuestro juicio debe partirse de un análisis de casos-tipo, materializando indices de valoración $y$ estableciendo criterios para su generalización. Las tablas o baremos debe $\mathrm{n}$ s e $\mathrm{r}$ revisados periódicamente para recoger las oscilaciones de mercado y signo monetario.

Como el fin último del inventario es poner de manifiesto el potencial económico del Estado, reviste extraordinario interés y resulta muy delicado el aspecto de valoración de bienes y derechos, el cual, por otra parte, exige una clasificación de aquéllos, considerados bajo criterio particular, y que difiere de las que hicimos anteriormente en muchos aspectos. Enunciemos, a modo de ejemplo, esa clasificación:

A. InMUebles. - 1. Inmovilizados: a) Afectados a servicios, y b) Idem a negocios.-2. Movilizados; a) Arren- 
dados o cedidos, y b) En estado de venta.

B. Muebles: 1. Máquinas, medios de transporte y asimilados.-2. Mobiliario, armas, colecciones, útiles $\mathrm{y}$ enseres, herramientas e instrumentos y bienes de uso precario.-3. Bienes nuevos en almacenes y depósitos. - 4. Bienes innecesarios o inútiles.

C. Semovientes: Equinos, bovinos, etc.

D. Valores FINANCIEROS: Inversiones inmovilizadas; numerario libre de afectaciones; valores mobiliarios; valores exigibles; créditos y pagos a cuenta de bienes no recibidos. Con respecto a estos últimos, creemos que sólo el concepto de valores mobiliarios forma parte del inventario general, pues los demás aspectos deben inventariarse por Centros del Ministerio de Hacienda distintos de la Dirección General del Patrimonio del Estado.

El valor de los bienes y derechos del Estado (sea de coste en origen, de valor potencial íntegro, de valor potencial residual, de valor de reposición o de valor de mercado) es una magnitud que se expresa siempre en términos relativos; no sólo porque puede contemplar los bienes según naturaleza, duración, estado de conservación, afectación, implicación, etc., sino porque el valor se estima en moneda, y ésta por si misma constituye un signo convencional.

El valor integro de reposición se aplica generalmente a bienes (de carácter mueble principalmente), de los cuales puede decirse que, mientras prestan servicio, su rendimiento no aumenta ni disminuye, no admitiendo graduación alguna entre el calificativo de útiles y el de inútiles.
Por último, el valor de mercado debe aplicarse, dentro de ciertos márgenes de tolerancia, a bienes patrimoniales; es decir, a aquellos que, mediata $o$ inmediatamente, pueden ser objeto de comercio, ya se trate de inmuebles o bienes de carácter mueble. Los ciclos de vigencia de las valoraciones deben ser más cortos en bienes patrimoniales que en bienes de servicio público, aun tratándose de las mismas especies.

De todos modos, no es posible establecer una teoría de criterios sobre estimación de valores y ciclos de duración de los mismos, sin planificar previamente la contabilidad patrimonial.

\section{El criterio en la confección del inventario}

Si la unidad de criterio es indispensable para cuanto deba expresarse con palabras, mucho más 10 ES para lo que se deba expresar en cifras; porque el inventario va poniendo de manifiesto unos datos que la contabilidad y la estadística se encargan de resumir; y no pueden sumarse cifras de renta o de venta estimadas con criterio inflacionista, con otras estimadas con criterio deflacionista, porque son de signo contrario y el resultado carecería de significación.

\section{Perpetuidad y honradez del inventario}

De las instrucciones cursadas por la Dirección General del Patrimonio del Estado se deduce que no se trata de hacer, como en ocasiones anteriores, un inventario de meras 
circunstancias (para liquidar, por ejemplo, unos bienes que ocasionalmente han tenido acceso al Patrimonio), sino de hacer un inventario perpetuo. Importa mucho, por tanto, evitar todo error en su confección, pues se supone que las fichas deben tener tantos años de vigencia cuantos sean los de uso de los bienes; y en inmuebles hay que calcularlos por décadas, y en algunos casos quizá por siglos. El rigor en la toma de datos debe ser mayor cuanto más duración se suponga a las fichas. De lo expuesto se deduce que muchas razones obligan a confeccionar el inventario con pulcritud, paciencia y honradez. Tanta importancia reviste la confección como la actualización del inventario. La muerte de algunos inventarios (fiscales $\mathrm{y}$ no fiscales) realizados por la Hacienda la produjo su prematuro envejecimiento, ocurrido por falta de atención en su conservación. Por tanto, la idea de un inventario estático debe ser desechada y aceptarse sin dudar la de un inventario dinámico. Muchos factores deben ser conjugados para el buen funcionamiento del inventario, pero ninguno debe despreciarse si se acepta la lección de anteriores experiencias, que derivaron en fracasos por falta de las previsiones necesarias, sobre todo en el área de su conservación.

IX. Unidad en los principios, unidad en lo dominical, unidad en lo orgánico $y$ respeto al contribuyente

Al multiplicarse la actividad del Estado, tan intensa $y$ extensamente, en el último cuarto de siglo han crecido sus medios de acción tan vertiginosamente, que ya no es posible ocultar la existencia de una nueva Hacienda en bienes y derechos; de una Hacienda que, si por su naturaleza reclama trato diferente, por su importancia exige quizá tanta atención como la de los tributos.

¿En cuánto se valora este nuevo aspecto de la Hacienda?... ¿Qué rentas produce, o mejor dicho, ahorra? Sumando $\mathrm{s}$ u s distintas fracciones (bienes patrimoniales, bienes de servicio público, bienes nacionales), ise obtendrá una cifra aproximada a la de un presupuesto?... Estos son enigmas que sólo puede descifrar el inventario una vez ultimado.

El principio de división del trabajo ha obligado a la especialización de funciones, pero en materia patrimonial, si se exceptúan las ramas castrenses, que brindan su ejemplo a la administración civil, en lo que a organización de uservicios» se refiere, lo patrimonial ni se ha racionalizado ni se $h$ a especializado; pues cada Organismo tiene que simultanear con su función especifica, la de adquisición, construcción y conservación de los bienes que deben constituir el equipo necesario para su instalación y desenvolvimiento, lo cual no conduce más que a un despilfarro de energias $y$ de dinero.

El remedio de todo esto puede venir de la Ley de Bases del Patrimonio del Estado, pues su aparición denota que el Ministerio de Hacienda comienza a inquietarse por cuanto afecta a las propiedades y derechos del Estado; sometiendo en efecto su gobierno a normas generales, por supuesto inspiradas en los únicos y valederos principios; aquellos que, partiendo de la unidad pa- 
trimonial conducen a la última $y$ única finalidad deseable, el bien general.

Por otra parte, la unidad patrimonial exige la unidad orgánica, o por lo menos la funcional, y ésta a su vez impone, como materia de cohesión, un cuerpo especial de funcionarios que tenga por misión fundamental atender a estos servicios.

La Hacienda Pública, tan obligada con los buenos contribuyentes, en su nombre y representación, debe com- prometerse a simultanear dos acciones diferentes: $a$ ) Traer al buen camino a los contribuyentes morosos, y b) Garantizar a unos y otros la útil inversión del total producto de los tributos. Partiendo de esta dualidad se llega a la conclusión de que existe la misma razón para una -eficaz inspección de tributos que para una celosa vigilancia de las inversiones, sobre todo de las inmovilizadas. - Leonardo Escribano MONGE. 